\title{
Reduced purine 5'-nucleotidase activity in lymphocytes of patients with systemic lupus erythematosus: results of a pilot study
}

Departments of Rheumatology J N Stolk

L B A van de Putte A M Th Boerbooms

Paediatrics (Laboratory of Purine and Pyrimidine

Metabolism)

R A De Abreu

D G M de Koning

and Haematology

A $\mathrm{H}$ Pennings

University Hospital Nijmegen, Nijmegen, the Netherlands

Correspondence to: Dr J N Stolk, Department of Rheumatology, University Hospital Nijmegen, PO Box 9101, 6500 HB Nijmegen, the Netherlands. 2 November 1998
Accepted for publication

\begin{abstract}
Jan N Stolk, Diana G M de Koning, Arie H Pennings, Ronney A De Abreu, Leo B A van de Putte, Agnes M Th Boerbooms
\end{abstract}

\begin{abstract}
Objective-To investigate purine metabolism in patients with systemic lupus erythematosus (SLE) for possible abnormalities that might be related to their overall impaired immune function.

Methods-This pilot study included 17 patients with SLE ( 2 men, 15 women). Enzyme activities of the purine enzymes $5^{\prime}$-nucleotidase $\left(5^{\prime} \mathrm{NT}\right)$, purine nucleoside phosphorylase (PNP), and hypoxanthineguanine-phosphoribosyltransferase

(HGPRT) were measured in peripheral blood mononuclear cells (PBMC) and also in fractions of $T$ cells (differentiation antigen $\mathrm{CD3}+)(\mathrm{n}=12)$ and $\mathrm{B}$ cells $(C D 19+)(n=9)$. The activity of the thiopurine enzyme thiopurine-methyltransferase (TPMT) was measured in red cell lysate. Routine blood tests and indices of disease
\end{abstract}

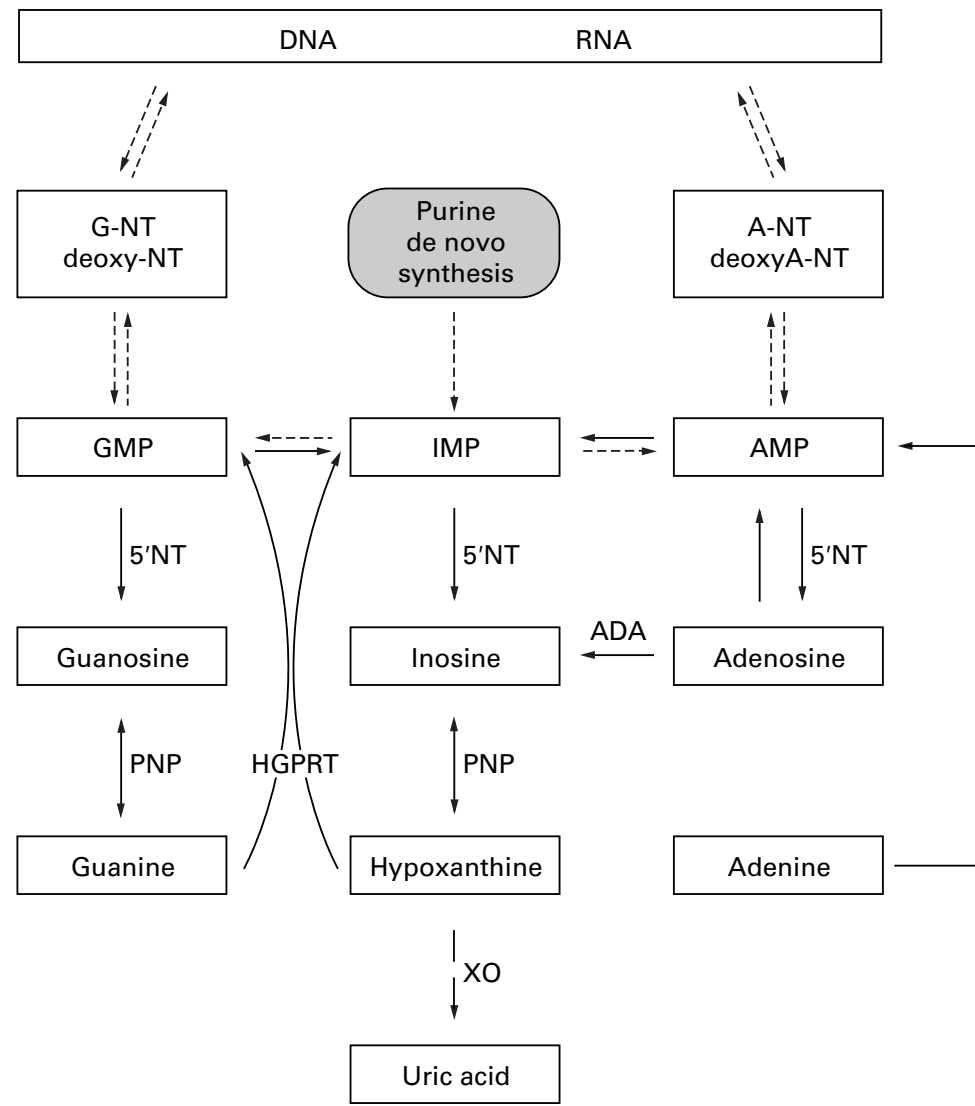

Figure 1 Simplified scheme of purine metabolism. G: guanine; NT: nucleotides; A: adenine; GMP: guanosine monophosphate; IMP: inosine monophosphate; AMP: adenosine monophosphate; 5'NT: 5'-nucleotidase; ADA: adenosine deaminase; HGPRT:

hypoxanthine-guanine-phosphoribosyltransferase; PNP: purine nucleoside phosphorylase. activity were measured as well. Results were compared with those of healthy volunteers.

Results-Compared with their controls, the female SLE patients had a more than $50 \%$ reduced activity of 5 'NT in the $T$ cell fraction $(p=0.001)$ and in PBMC ( $p<$ $0.000)$. 5'NT activity was also lower in $B$ cells, but this was not statistically significant. Enzyme activities did not correlate with indices of disease activity, disease duration or the $B$ cell/ $T$ cell ratio and no influence of medication was found.

Conclusion-Reduced lymphocyte 5'NT activity is a novel finding in SLE. These results indicate that purine metabolism in SLE may be disturbed. Consequences of a low 5'NT activity may be an intracellular accumulation of (deoxy)purine nucleotides and a reduction of adenosine production. It is hypothesised that these factors may play a part in the overall impaired immune function and in the chronicity of inflammation in SLE. (Ann Rheum Dis 1999;58:122-125)

In systemic lupus erythematosus (SLE), impaired immune reactivity has been reported both in vivo and in vitro. This concerns humoral as well as cellular immunity. ${ }^{12}$ Subsequently, infections are a major cause of morbidity and mortality in SLE.

Impairment of the immune response and increased mortality caused by infections are also the hallmarks of inborn deficiencies of some purine enzymes such as adenosine deaminase (ADA), ${ }^{3}$ purine nucleoside phosphorylase (PNP), ${ }^{4}$ and 5 '-nucleotidase (5’NT). ${ }^{5}$ (Figure 1).

Studying purine enzymes in SLE may be of interest for several reasons. Firstly, because the disease is frequently treated with azathioprine (AZA), a hypoxanthine analogue and immunosuppressive drug that is largely metabolised by purine enzymes and a specific catabolic thiopurine enzyme, thiopurine-methyltransferase (TPMT). And secondly, because deficiencies of purine enzymes may be associated with impairment of the immune system and the occurrence of autoimmune disorders, ${ }^{4}$ of which SLE may be considered as the "classic" example.

To investigate thiopurine metabolism for abnormalities that might be associated with immune dysfunction, we conducted a pilot study in patients with SLE. 
Table 1 Enzyme activities by group and cell type

\begin{tabular}{lllll}
\hline Enzyme & Cell type & SLE & Controls & p value \\
\hline $5^{\prime} \mathrm{NT}^{\star}$ & PBMC & $9.4(6.4)$ & $21.9(8.3)$ & $<0.000 \dagger$ \\
& T cells & $10.7(5.5)$ & $22.2(6.4)$ & $=0.001 \ddagger$ \\
\multirow{2}{*}{ HGPRT } & B cells & $41.1(32.6)$ & $56.1(25.4)$ & NS \\
& PBMC & $7.5(2.5)$ & $9.7(3.9)$ & $=0.03 \dagger$ \\
& T cells & $5.5(1.9)$ & $4.9(1.9)$ & $\mathrm{NS}$ \\
PNP & B cells & $3.8(1.6)$ & $4.2(0.9)$ & $\mathrm{NS}$ \\
& PBMC & $170(70)$ & $176(55)$ & $\mathrm{NS}$ \\
& T cells & $101(31)$ & $101(36)$ & $\mathrm{NS}$ \\
\multirow{2}{*}{ TPMT } & B cells & $77(39)$ & $75(19)$ & $\mathrm{NS}$ \\
& Ery-lysate & $19.6(4.6)$ & $22.6(4.1)$ & $=0.05 \ddagger$ \\
\hline
\end{tabular}

${ }^{\star}{ }^{\prime}$ 'NT activities of women only. Values are means (SD). 5'NT, HGPRT, and PNP activities are in $\left(\mathrm{nmol} / 10^{6}\right.$ viable cells $/ \mathrm{h}$ ) TPMT activity is in (pmol/ $10^{6}$ cells $\left./ \mathrm{h}\right) . \dagger t$ test, $\ddagger$ Mann-Whitney $\mathrm{U}$ test, NS: not significant.

\section{Methods}

PATIENTS

The study group consisted of 17 patients (15 women, 2 men) with established SLE according to the 1982 revised criteria for classification of SLE. Of these patients, one was untreated, nine used prednisone only, six used prednisone plus azathioprine, and one was taking azathioprine only. Controls were 43 healthy volunteers (26 women, 17 men). Baseline characteristics (mean (SD)) of the patients were: age: 46.4 (18.6) years (range 20-76), disease duration: 155 (121) months, prednisone dose: 7.3 (3.6) $\mathrm{mg}$ /day (range 2.5-15), azathioprine dose: 121 (40) $\mathrm{mg}$ /day (range 100-200). The controls' age (mean (SD)) was: 43.9 (9.2) years (range 26-63).

\section{MEASUREMENTS}

Laboratory tests consisted of a haematological (cell counts) and biochemical (kidney and liver function, serum uric acid) profile and measurement of the main laboratory indices of disease activity (erythrocyte sedimentation rate (ESR), complement factors $\mathrm{C} 3 / \mathrm{C} 4$, and the titre of anti-dsDNA antibodies). In addition, the SLE disease activity index (SLEDAI) was calculated. To avoid influences of possible circadian rhythms blood sampling was done between 9 and 11 am in all participants.

ISOLATION OF CELLS

Peripheral blood mononuclear cells (PBMC) were obtained by Ficoll-Isopaque gradient centrifugation (density $1.077 \mathrm{~g} / \mathrm{ml}$, Nycomed) of a sample of defibrinated venous blood. ${ }^{6} \mathrm{~A}$ part of these cells was stained with fluorescent conjugated monoclonal antibodies. The fluorochromes were fluorescein in its isothiocyanate form (FITC) and phycoerythrin (PE). The conjugates were CD3-PE and CD19-FITC (Dako). Bulk sorting of CD3+ $\mathrm{T}$ cells and CD19+ B cells was performed on a Coulter Epics Elite Flow Cytometer (Coulter).

ENZYME ASSAYS

Activities of the salvage key enzymes 5'NT, PNP, and hypoxanthine-guanine-phosphoribosyltransferase (HGPRT) were measured in PBMC (all patients and controls) and also in $\mathrm{T}$ cell $(\mathrm{CD} 3+)$ fractions (12 patients, 8 controls) and $\mathrm{B}$ cell (CD19+) fractions (9 patients, 8 controls), obtained by fluorescence activated cell sorting. TPMT was measured in erythrocyte lysate. Enzyme activities are expressed in

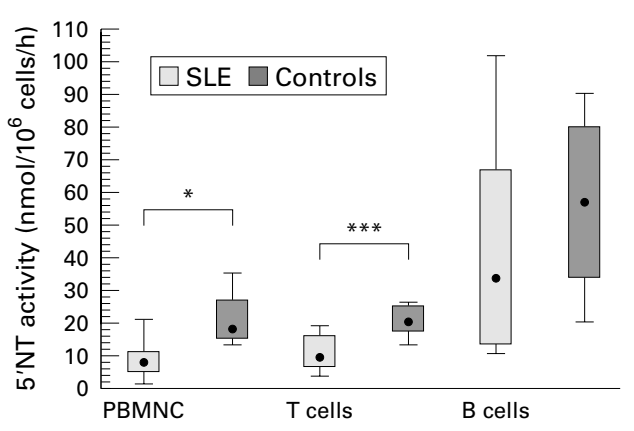

Figure 2 Box plot representation of purine 5'-nucleotidase activity in female SLE patients and female controls. $A$ box represents the 25-75 percentile range, the lines the 10-90 percentile range and the black dot within the box the median value. ${ }^{\star} p<0.000,{ }^{\star \star \star} p=0.001$.

(nmol/10 ${ }^{6}$ viable cells/h), except for the TPMT activity, which is expressed in $\left(\mathrm{pmol} / 10^{6}\right.$ cells/h). ${ }^{67}$ The assays were done in quadruplicate.

STATISTICAL ANALYSES

The activity of 5'NT is influenced by age and sex. ${ }^{78}$ Therefore, these activities were adjusted for age by using results of linear regression analyses as described before ${ }^{7}$ and, because of the small number (two), the male activities were excluded from the statistical analyses of 5'NT. To compare the enzyme activities of patients and controls statistical analyses consisted of $t$ tests (PBMC) and of Mann-Whitney $\mathrm{U}$ tests. Influence of medication was analysed by grouping the patients according to their treatment and performing a Kruskall-Wallis test. Associations of indices of disease activity, disease duration, and $\mathrm{B}$ cell/T cell ratio with enzyme activities were analysed with correlation coefficients according to Spearman. The statistics were processed by SPSS computer software (version 6.1). Results were considered to be significant at $\mathrm{p}$ values $\leqslant 0.05$.

\section{Results}

ENZYME ACTIVITIES

Table 1 shows the mean enzyme activities in the different cell types. In female patients, activities of 5 'NT were significantly lower in PBMC and in T lymphocytes. Activities in B lymphocytes were also lower but the difference did not reach statistical significance. In one of the two male patients we found a mean PBMC 5'NT activity, $21.3 \mathrm{nmol} / 10^{6}$ cells/h (PBMC normal range of male controls: 4.1-21.6; mean $\left.13.4 \mathrm{nmol} / 10^{6} \mathrm{cells} / \mathrm{h}\right)$. The other man showed a mean $5^{\prime} \mathrm{NT}$ activity of 6.4 in PBMC and a mean 5'NT activity in T cells of 3.1 ( $\mathrm{T}$ cell normal range of male controls: 3.4-20.2; mean $11.3 \mathrm{nmol} / 10^{6}$ cells $/ \mathrm{h}$ ). His mean B cell activity was 45.6 (B cell normal range of male controls: $8.6-52.2$; mean $35.6 \mathrm{nmol} / 10^{6}$ cells $/ \mathrm{h}$ ). Figure 2 shows the percentile distribution of 5'NT activity in female patients and controls. Activities of PNP were not different in patients and controls but those of HGPRT in PBMC and TPMT were slightly but significantly lower in SLE. 
ENZYME ACTIVITIES AND CORRELATIONS WITH DISEASE ACTIVITY, DISEASE DURATION, MEDICATION, AND B CELL/T CELL RATIO SLEDAI values of the female patients ranged between 0-12; mean (SD): 3.6 (3.5). We neither found significant correlations between enzyme activities and the main laboratory indices of disease activity (data not shown), nor between enzyme activities and the SLEDAI (Spearman correlation coefficients of SLEDAI with 5'NT activity in PBMC, $\mathrm{T}$ cells, and $\mathrm{B}$ cells were respectively: $r=-0.35, \mathrm{p}=0.22 ; r=$ $0.02, \mathrm{p}=0.95$, and $r=0.42, \mathrm{p}=0.30)$. Also between enzyme activities and disease duration we found no significant correlations (data not shown), with exception of the HGPRT activity, which showed an inverse relation with disease duration (Spearman $r=-0.48, \mathrm{p}=0.05$ ). Furthermore, indices of disease activity and enzyme activities were found not to be influenced by the medication used. KruskalWallis test results for the influence of medication on 5'NT activity in the different cells were: PBMC: $p=0.44$; T cells: $p=0.59$ and $B$ cells: $\mathrm{p}=0.44$. Mann-Whitney tests on the results of cell sorting, showed that female patients compared with controls respectively, had a lower percentage of B cells (3.5 (2.5) $v 5.8$ (1.7); $\mathrm{p}=0.05)$, a higher percentage of $\mathrm{T}$ cells (86.3 (7.7) v 77.0 (9.5); $\mathrm{p}=0.04)$, similar total percentages of lymphocytes $(65.8$ (12.2) $v 72.5$ (13.8); $\mathrm{p}=0.24)$ and a lower ratio of $\mathrm{B}$ cells/ $\mathrm{T}$ cells $(0.043(0.033) v 0.079(0.033) ; \mathrm{p}=0.05)$. Finally, in female patients and controls, Spearman correlation coefficients were used to analyse the relation between 5'NT activities of the three cell types and the $\mathrm{B}$ cell/ $\mathrm{T}$ cell ratio. The highest correlation was found in patients in the $\mathrm{B}$ cells with $r=-0.65 ; \mathrm{p}=0.06$. All the other correlation coefficients in patients and controls were lower than 0.43 with $p$ values $\geqslant 0.34$.

\section{Discussion}

An interesting and novel finding in SLE is the more than $50 \%$ reduced mean $\mathrm{T}$ cell purine ${ }^{\prime} \mathrm{NT}$ activity. In addition, a number of patients also have a considerably lower B cell 5'NT activity. It seems plausible that the significantly reduced $5^{\prime} \mathrm{NT}$ activity in PBMC is partly a reflection of the $\mathrm{T}$ and $\mathrm{B}$ cell activities and the decreased percentage of $\mathrm{B}$ cells. The differences we found in the activities of HGPRT and TPMT are small and it is questionable whether they are clinically relevant. In this pilot study, especially with respect to 5'NT, we could neither find correlations between the enzyme activities and indices of disease activity, disease duration or $\mathrm{B}$ cell/T cell ratio, nor relations between the enzyme activities and the used medication.

Purine $5^{\prime} \mathrm{NT}$ is a rate limiting catabolic enzyme that hydrolyses mononucleotides and deoxymononucleotides to their respective nucleosides or deoxynucleosides. The enzyme is located in the plasma membrane as membrane bound ecto-5'NT. There is also a soluble form in the cytoplasmic matrix. ${ }^{5}$ Both types of $5^{\prime} \mathrm{NT}$ can be detected in a large variety of human tissues, suggesting that this enzyme has a key role in normal cell function.
Cytoplasmic 5'NT dephosphorylates intracellular nucleotides of guanine, inosine, and adenine to their respective nucleosides by which it plays a key part in the turnover of nucleic acids and the maintenance of constant intracellular nucleotide pools. ${ }^{9}$ In our experiments total 5'NT activity was measured because it is largely determined by the cytoplasmic fraction, ${ }^{9}$ which may be important in lymphocytotoxicity.

In blood lymphocytes, reduced 5'NT activity may be caused by an increased number of circulating immature cells, ${ }^{10}$ by a diminished

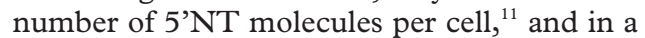
$\mathrm{T}$ cell fraction by an increased CD4/CD8 ratio. In SLE however, the latter mentioned possibility seems less plausible because various studies on this issue have given conflicting results ${ }^{12}$ and in our opinion the most probable explanation seems to be a combination of the above mentioned factors, especially of the first two, together with a relatively more reduced cytoplasmic 5'NT activity.

A reduced $5^{\prime} \mathrm{NT}$ activity may result in two main effects. In the extracellular compartment, the supply of (deoxy)nucleosides will diminish and may lead to a decreased salvage. Intracellularly, it generates accumulation of (deoxy) nucleotides. Conceivably, this will disrupt homeostasis of purine metabolism and the processes of DNA and RNA synthesis and repair. Subsequently, this may interfere with normal cell function, cause lymphocytotoxicity and a diminished immune function. In deficiencies of ADA and PNP, raised levels of deoxyATP and deoxyGTP respectively, are responsible for the toxic effects on lymphocytes. ${ }^{12}{ }^{13}$ We hypothesise that by means of low 5'NT activity, a similar, although attenuated, kind of toxicity may be present in SLE. Observations of delayed repair of DNA damage $^{14}$ and increased frequencies of sister chromatide exchange ${ }^{15}$ in lymphocytes of patients with SLE may fit well into this hypothesis.

Low 5'NT activity may also result in a reduced release of adenosine, which is a purine derivative with anti-inflammatory properties. ${ }^{16}$ It is not inconceivable that a diminished production of adenosine, caused by a widespread reduced level of 5'NT activity, leads to a decreased endogenous anti-inflammatory capacity and plays a part in the persistence of inflammation in SLE.

Recently we published studies on thiopurine enzyme activities in recent onset rheumatoid arthritis $^{7}$ and during AZA treatment in rheumatoid arthritis, ${ }^{8}$ comprising also the enzyme activities of the patients that received AZA for six months while it was well tolerated. If we compare these activities with those of the SLE patients in PBMC, only 5'NT activity differs and is markedly lower in SLE. In our opinion this finding supports our idea that the low 5'NT activity in SLE may be a disease related phenomenon.

We realise that the number of 17 patients seems rather small. However, the substantial differences between 5'NT activities seem reliable, not only because of the clear cut 
results of statistics, but also because of the use of enzyme assays with good reproducibility. ${ }^{8}$

In conclusion, the reduced $5^{\prime} \mathrm{NT}$ activity in SLE is a new finding and puts its impaired immune function and chronic inflammation in a different light. From the results of this pilot study, conclusions about the role of $5^{\prime} \mathrm{NT}$ in the pathogenesis of the disease can hardly be drawn. However, the presence of the reduced 5'NT activity in most of the patients and the absence of relations between enzyme activity on the one hand and disease activity, disease duration, B cell/T cell ratio or the used medication on the other hand, suggests that

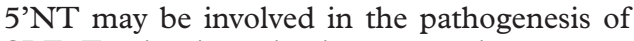
SLE. Further investigations on purine enzyme activities and metabolism in SLE are necessary, and these should contain larger groups of patients, patients in the early stage of the disease before treatment, and follow up data. In addition, the exact origin of the low 5'NT activity has to be determined as well as its significance in relation to the disturbed immune function and the chronicity of the inflammatory processes.

The authors wish to thank Mrs G Vierwinden, Department of Haematology, Central Laboratory of Haematology, for labelling and sorting of the lymphocytes.

Funding: this study was supported by a grant from: "Het Nationaal Reumafonds" of the Netherlands (The Dutch League against Rheumatism).

1 Tsokos GC. An overview of cellular immune function in systemic lupus erythematosus. Chapter 2. In: Lahita RG, ed. Systemic lupus erythematosus. 2nd edition. New York: Churchill Livingstone, 1992.

2 Horwitz DA. Systemic lupus erythematosus: generalized autoimmunity arising from disordered immune regulation. Chapter 69. In: McCarty DJ, Koopman WJ, eds. Arthritis and allied conditions. 12th edition. Philadelphia: Lea and Febiger, 1993.
3 Thompson LF, Seegmiller JE. Adenosine deaminase deficiency and severe combined immunodeficiency disease. ciency and severe combined im

4 Markert ML. Purine nucleoside phosphorylase deficiency. Immunodeficiency Rev 1991;3:45-81.

5 Sunderman FW jr. The clinical biochemistry of 5'Nucleotidase. Ann Clin Lab Sci 1990;20:123-39.

6 Stolk JN, De Abreu RA, Boerbooms AMTh, de Koning DGM, de Graaf R, Kerstens PJSM, et al. Purine enzyme activities in peripheral mononuclear cells: comparison of a new non-radiochemical high-performance liquid chromatography procedure and a radiochemical thin-layer chrotography procedure and a radiochemical thin-layer chro-
matography procedure. J Cromatogr B 1995;666:33-43.

7 Stolk JN, Boerbooms AMTh, De Abreu RA, Kerstens PJSM, de Koning DGM, de Graaf R, Mulder J, et al. Purine enzyme activities in recent onset rheumatoid arthritis: are there differences between patients and healthy controls? Ann Rheum Dis 1996;55:733-8.

8 Stolk JN, Boerbooms AMTh, De Abreu RA, de Koning DGM, van Beusekom HJ, Hissink Muller W, et al. Reduced thiopurine-methyltransferase activity and development of side effects on azathioprine in the treatment of rheumatoid arthritis. Arthritis Rheum 1998;41:1858-66.

9 Edwards NL, Recker D, Manfredi J, Rembecki R, Fox IH. Regulation of purine metabolism by plasma membrane and cytoplasmic 5'-nucleotidase. Am J Physiol 1982;243: C270-7.

10 Edwards NL, Gelfand EW, Burk L, Dosch HM, Fox IH. Distribution of 5'-nucleotidase in human lymphoid tissues. Proc Natl Acad Sci USA 1979;7:3474-6.

11 Thompson LF, Ruedi JM, Low MG, Clement LT. Distribution of ecto-5'-nucleotidase on subsets of human T and B Iymphocytes as detected by indirect immunofluorescence using goat antibodies. J Immunol 1987;139:4042-8.

12 Stone TW, Simmonds HA. Clinical consequences of aberrant purine metabolism. Chapter 11. In: Stone TW, Simmonds HA, eds. Purines: basic and clinical aspects. Dordrecht: Kluwer Academic Publishers, 1991

13 Carson DA, Carrera CJ, Wasson DB, Iizasa T. Deoxyadenosine-resistent human $\mathrm{T}$ lymphoblasts with elevated 5'-nucleotidase activity. Biochim Biophys Acta 1991;1091:22-8.

14 McCurdy D, Tai LQ, Frias S, Wang Z. Delayed repair of DNA damage by ionizing radiation in cells from patients with juvenile systemic lupus erythematosus and rheumawith juvenile systemic lupus erythematosus
toid arthritis. Radiat Res 1997;147:48-54.

15 Palmer RG, Dore CJ, Denman AM. Sister-chromatid exchange frequencies in lymphocytes of controls and patients with connective tissue diseases. Mutat Res 1986;162:113-20.

16 Gadangi P, Longaker M, Naime D, Levin RI, Recht PA, Montesinos MC, et al. The anti-inflammatory mechanism of sulfasalazine is related to adenosine release at inflamed sites. J Immunol 1996;156:1937-41. 